ISSN 1112-9867

Available online at http://www.jfas.info

\title{
EFFECT OF AGGREGATE GRAIN SIZE DISTRIBUTION ON PROPERTIES OF PERMEABLE CONCRETE
}

\author{
Ş. Yazici ${ }^{1}$, A. Mardani-Aghabaglou $*^{2}$ \\ ${ }^{1}$ Department of Civil Engineering, Eng. Faculty, Ege University, Bornova- zmir, Turkey \\ ${ }^{2}$ Department of Civil Engineering, Eng. Faculty, Uludağ University, Nilüfer-Bursa, Turkey
}

Received: 27 June 2016 / Accepted: 27 December 2016 / Published online: 01 January 2017

\begin{abstract}
In this study, the effect of aggregate grain size distribution and water/cement (W/C) ratio on the mechanical properties of permeable concrete is investigated. The aim of this study is to prepare permeable concrete mixture with optimum properties in terms of strength and permeability. For this purpose, five different permeable concrete mixtures with 0.3 constant W/C ratio and containing different proportions of coarse aggregate which are 5-15 and 15-25 $\mathrm{mm}$, but containing no fine aggregate are prepared. In addition, three different concrete mixtures with $0.35 \mathrm{~W} / \mathrm{C}$ ratio and containing $20 \%$ (by weight) fine aggregate and different proportions of coarse aggregate which are 5-15 $\mathrm{mm}$ and $15-25 \mathrm{~mm}$ are prepared. Afterwards, some tests related to the compressive strength, splitting tensile strength, flexural strength, ultrasonic pulse velocity (UPV) and permeability of concrete mixtures are conducted. Test results demonstrate that permeability, strength and UPV of the mixtures increased upon using $20 \mathrm{wt} \%$ of fine aggregate instead of coarse aggregate and upon reducing coarse aggregate grain diameter though $\mathrm{W} / \mathrm{C}$ ratio of mixtures increases from 0.3 to 0.35 .
\end{abstract}

Keywords: Permeable concrete, permeability, compressive strength, splitting tensile strength, flexural strength, ultrasonic pulse velocity

Author Correspondence, e-mail: ali.mardani16@ gmail.com doi: http://dx.doi.org/10.4314/jfas.v9i1.20 


\section{INTRODUCTION}

The first studies related with the permeable concrete have been conducted approximately 50 years ago in the United Kingdom, United States and Japan. There is also an increasing interest in this type of concrete recently. The most important properties of permeable concrete are to have large porosity between $15-35 \%$ that linked to each other within their structure. Thanks to the mentioned properties permeable concrete has a characteristic of high water permeability $[1,2]$. Thus, it helps to prevent accidents by reducing the puddle adversely affecting drivers. At the same time, it improves the road safety by reducing the road surface glare. In this way, the drivers are protected against accidents [3-5]. In the world where the urbanization keeps spreading, the rainwater flows into the rivers, lakes or seas swiftly without reaching underground. The permeable concrete can provide transferring of rainwater to the ground in a controlled manner. It can also be solution to environmental problems by preventing soil erosion. The cause of the increasing use of pervious concrete in addition to a variety of its environmental benefit is to good flow of water from its structure as well as to reduce the pollution of ground by feeding ground water [6].

Presence of more porosity in the structure of permeable concrete increases the permeability of the concrete whereas the mechanical properties are affected negatively [1, 2, 7]. Permeable concrete can be used for the coating of pavements which are not exposed to heavy loads as well as sports fields and parking areas that are generally subjected to rainfall. Permeable concrete can eliminate the complex drainage system requirements by providing the leak of rain water from traffic surface [8-14].

Compressive strength of the permeable concrete is affected by W/C ratio, aggregate-binding ratio, aggregate grain diameter, casting, compacting, finishing and curing conditions. Generally, compressive strength of permeable concrete varies between 5 and $30 \mathrm{MPa}$ [15]. As it is shown in test results, permeable concrete mixtures have the ability to store and hold the water within its structure. The mentioned stored water is equal to the water required for 1 month irrigation of $10 \mathrm{~m}^{2}$ garden during a dry season [16]. The results of some related studies are summarized below.

The effect of W/C ratio and coarse aggregate content on the properties of permeable concrete was investigated in a study. Compressive strength and unit weight of the permeable concrete mixtures increased; however, their void ratio and permeability decreased with the decrease in $\mathrm{W} / \mathrm{C}$ ratio. At the same time, W/C ratio, permeability and void ratio of permeable concrete decreased; however, its compressive strength and unit weight arised with the increase in cement content. Increasing coarse aggregate content caused a reduction in the unit weight of 
the mixture as well as causing an increase in the void ratio and permeability of the mixture [17].

Low strength of permeable concrete was increased with the addition of fine aggregate. This fact was more obvious with the increase in fine aggregate content [18]. Water permeability decreases at the same time. Neptune [19] claimed that there is an inverse relationship between water permeability and strength properties of the permeable concrete. Besides, it was also reported that there occurred an increase in the compressive strength and reduction in permeability of concrete by increasing its void ratio.

Strength, fracture and fatigue of permeable concrete were investigated by Chen et. al., [20]. The results indicate that flexural strength of the concrete is more sensitive to porosity than compressive strength. Permeable concrete has more significant size effect than conventional concrete. Polymer-modified pervious concrete demonstrates much higher fracture toughness and far longer fatigue life than supplementary cementitious material-modified pervious concrete at any stress level.

Bing et. al., [21] stated that the ratio of cement paste / mortar should be in the ideal value within the permeable concrete. In the absence of adequate mortar content for covering aggregate surface in the permeable concrete, aggregate cannot be held on to each other, hence compressive strength of the mixture decreases. In the presence of high cement paste/mortar ratio, permeability of the concrete decreases.

Microscopic analysis of paste and aggregate distresses in pervious concrete in a wet, hard freeze climate was investigated by Vancura et. al., [22] in another study. As a result of the investigation, it is found out that freeze/thaw distresses were the suspected cause of a majority of the subsurface cracks due to the similarity of the cracking patterns in the previous concrete to cracking patterns in conventional concrete that were caused by freeze/thaw damage. While it was revealed that the freeze/thaw damage was the cause for the subsurface cracks in the previous concrete samples, the cracking patterns were not consistent throughout the samples. Furthermore, the cracking patterns were not contingent upon the concrete mixture designs or aggregate type.

Bing et. al., [21] stated that the size of aggregate and specific gravity of cement affected the permeability of permeable concrete significantly. A reduction was observed in the permeability parameter of permeable concrete by decreasing aggregate grain diameter at the same mix proportion.

There are several different studies about properties of permeable concrete in the literature [2331]. However, the aim of this study is to prepare the optimum permeable concrete in terms of 
strength and permeability by considering the effect of aggregate grain distribution and W/C ratio of concrete mixture. The experimental study was performed in two stages. During the first stage, 5 different concrete mixtures with $0.3 \mathrm{~W} / \mathrm{C}$ ratio and containing different amounts of, $5-15 \mathrm{~mm}$ and $15-25 \mathrm{~mm}$, aggregate size fraction were prepared in the absence of fine aggregate. During the second stage of the study, 3 different mixtures with $0.35 \mathrm{~W} / \mathrm{C}$ ratio and containing 20\% 0-3 mm fine aggregate and different proportions of, 5-15 mm and 15-25 mm, aggregate size fraction were designed. Therefore, 8 different permeable concrete mixtures were prepared. The compressive strength, splitting tensile strength, flexural strength, ultrasonic pulse velocity and water permeability of the concrete mixtures were investigated.

\section{EXPERIMENTAL STUDY}

\subsection{Materials}

In this study, a CEMI42.5 R type cement is used as binder. The chemical and some physical properties of the cement obtained from the producer are shown in Table 1. 0-3 mm, 5-15 mm and 15-25 mm sized fraction crushed limestone aggregates are used during the preparation of the mixtures. The sieve analysis results and some physical properties of the aggregate are shown in Table 2 and 3 respectively. The specific gravity, water absorption capacity and unit weight of the aggregates are determined in accordance with EN 1097-6 and EN 1097-3 standards respectively.

8 different permeable concrete mixtures with two different W/C ratios and containing different aggregate proportions were prepared. Cement and air content were kept constant as $300 \mathrm{~kg} / \mathrm{m}^{3}$ and $20 \%$ (by volume) in all of the mixtures. The corrected mix proportion of the permeable mixtures as well as their theoretical and measured unit weight values are given in the Table 4. As it can be seen from Table 4, two permeable concrete series were prepared. The $\mathrm{C}$ series were without fine aggregate while $\mathrm{C} 1$ contained $100 \%$ 5-15 mm aggregate size fraction. In C2 mixtures $100 \%$ of $15-25 \mathrm{~mm}$ aggregate size fraction was used. However, in the C3, C4 and C5 mixtures, 5-15 mm aggregate was replaced with 15-25 mm aggregate as 25\%, $50 \%$ and $75 \%$. In the D concrete series, in addition to coarse aggregate, fine aggregate was used as $20 \mathrm{wt} \%$ of total aggregate content. In D1 and D2 mixtures, in addition to fine aggregate (as $20 \mathrm{wt} \%$ of total aggregate content), 80\% of 5-15 $\mathrm{mm}$ and $15-25 \mathrm{~mm}$ aggregates were used respectively. In the D3 mixture 40\% 5-15 mm, 40\% 15-25 mm and 20\% of 0-3 mm aggregates were used.

The compressive strength, splitting tensile strength and ultrasonic pulse velocity of $150 \mathrm{~mm}$ cube specimens and center point flexural strength of 100x100x600 mm prism specimens were 
obtained during 28-day period in accordance with EN 12390-3 [38], EN 12390-6 [39], ASTM C597 [00] and EN 12390-5 [40] standards respectively. Besides, permeability of the concrete mixture was tested on $150 \mathrm{~mm}$ cube specimens at the end of 28-day water curing. As it is known, the void ratio of permeable concrete is much higher than that of the conventional concrete mixture. When the permeability of concrete mixture was measured in accordance with EN 12390-8 standard, the water was observed on the side surface of the concrete sample before reaching the lower surface. Hence, the permeability of the permeable concrete could not be measured in accordance with the standard methods. In order to measure the permeability of permeable concrete, the side surfaces of the cubes were sealed with an acrylic copolymer-based sealing material. As it is shown in Figure 2, the $500 \mathrm{ml}$ water was decanted into concrete sample and the chronometer was started. The chronometer was stopped upon seeing the water in the lower side of the concrete sample. The transition time of water from the concrete sample was measured. Besides, the water absorption capacity of the concrete mixtures was compared by measuring the amount of water passed from the concrete sample.

\section{TEST RESULTS AND DISCUSSION}

\subsection{Compressive, splitting tensile and flexural strength}

The 28-day compressive strength of $150 \mathrm{~mm}$ cubic permeable concrete mixtures are shown in Figure 2. As it can be seen from the Figure, 28-day compressive strength of $\mathrm{C}$ series mixture were determined as 6.1 to $8.2 \mathrm{MPa}$. The minimum compressive strength was found in $\mathrm{C} 1$ mixture containing $100 \%$ of $5-15 \mathrm{~mm}$ sized aggregate. Compared to the $\mathrm{C} 1 \mathrm{mixture}$, compressive strength of the mixture increased upon utilization of 15-25 mm sized aggregate. This was insistently stated for the mixture containing $50 \%$ of $5-15 \mathrm{~mm}$ and $15-25 \mathrm{~mm}$ sized aggregates. As it was mentioned earlier, $C$ series mixture contains no fine aggregate. Compared to the $\mathrm{C}$ series without fine aggregate, compressive strength of the mixture increased by using fine aggregate in spite of increasing W/C ratio of the mixture from 0.3 to 0.35. Thus, in this case, the sand proportion change factor was more effective on the compressive strength of the mixture compared to $\mathrm{W} / \mathrm{C}$ ratio factor. In the mixture containing fine aggregate (Series D), compressive strength of the mixtures was obtained as 11.69 to 16.88 MPa. The maximum performance in terms of compressive strength was shown in the D3 mixture containing 20\% 0-3 mm, 40\% 5-15 mm and 40\% 15-25 mm sized aggregates.

28-day-long splitting tensile and flexural strength of concrete specimens are shown in Figure 3 and 4 respectively. As it can be seen from test results, splitting tensile strength of $\mathrm{C}$ series mixture containing no fine aggregate varies from 1.22 to $1.76 \mathrm{MPa}$. Mentioned range for 
flexural strength was found between 1.5 and 1.82 MPa. Similar to compressive strength behavior, the maximum and minimum splitting tensile and flexural strength were found in $\mathrm{C} 1$ and C4 mixtures respectively. The performance of concrete mixture in terms of splitting tensile and flexural strength was improved by adding fine aggregate to the mixture. D3 mixture showed maximum splitting tensile and flexural strength.

The relationship between compressive strength - splitting tensile strength, and -flexural strength of the concrete mixture is shown in Figure 5. Figure 5 indicates that there is a strong relationship between strength parameters of concrete mixtures.

As it can be seen from the test results, in spite of higher W/C ratio of series D mixture compared to the series $\mathrm{C}$ mixture, this mixture showed compressive strength approximately 2 times higher than that of $\mathrm{C}$ series. Related to the aggregate proportion, the fill rate of the permeable concrete increased upon using fine aggregate. Hence, compressive strength of the mixture decreased in the absence of fine aggregate and with the increase in coarse aggregate grain diameter.

\subsection{Ultrasonic pulse velocity}

The UPV values of 28-day water cured $150 \mathrm{~mm}$ cubic concrete specimens are given in Figure 6. As it is known that the age, moisture condition, concrete porosity, aggregate type and ITZ characteristics can affect the UPV value of the concrete mixture. UPV value of C series mixture was changed in the range of 1.02 and $1.14 \mathrm{Km} / \mathrm{s}$. Mentioned range was found 1.17 and $1.49 \mathrm{Km} / \mathrm{s}$ for Series D. UPV values of all permeable concrete mixtures were lower than $2 \mathrm{Km} / \mathrm{s}$, the limit specified for weak concrete by Whitehurst [32]. The results indicate that UPV values of permeable concrete mixture were slightly increased by utilization of fine aggregate and decreasing coarse aggregate grain diameter in spite of increasing W/C ratio of the mixture. This fact is that due to reduction in void ratio of concrete mixture by adding fine aggregate particle, it acts as a filler. Besides, Figure 7 indicates that there is a strong relationship between compressive strength and UPV values as well as splitting tensile strength and UPV values of permeable concrete mixture.

\subsection{Permeability test results}

The permeability test results are given in Table 5. As it is known, the entrapped air and capillary porosity of the concrete affects the permeability of the concrete mixtures [33]. In D series mixture, W/C ratio of concrete mixture was increased from 0.3 to 0.35 by adding fine aggregate in order to provide adequate permeability properties for concrete mixture. Hence, D series mixture would be expected to be more permeable compared to that of the $\mathrm{C}$ series. However, the reverse results are obtained as it can be seen from Table 5. Thus, coarse 
aggregate gradation, aggregate proportion and its size fraction as well as presence of fine aggregate in the mixture are the other important factors influencing permeability of the concrete. The minimum permeability value is shown in D3 mixture due to its proper aggregate proportion. $\mathrm{C} 2$ mixture shows the best performance in terms of water permeability. The relationship between compressive strength and water permeability of permeable concrete mixture is shown in Figure 8. As it can be seen from the Figure, there is inverse linear relation between strength and permeability of the concrete as expected. Void ratio of the concrete mixture is high in the absence of fine aggregate. Concrete mixture showed lower performance in terms of strength due to its higher porosity. Permeability of concrete mixture decreased by presence of fine aggregate and by decreasing coarse aggregate grain diameter. When the compressive strength of concrete mixture has no big significance, $\mathrm{C}$ series mixture can be used as permeable concrete. D3 mixture shows best performance in terms of compressive strength; moreover, it shows acceptable water permeability character.

\section{CONCLUSION}

In accordance with the used materials and obtained results, following conclusions may be drawn:

It was observed that in the absence of fine aggregate, ultrasonic pulse velocity as well as compressive, splitting tensile and flexural strength of mixtures including just 15-25 mm or 5$15 \mathrm{~mm}$ sized aggregates were lower than the mixtures with both 15-25 and 5-15 mm sized aggregates. This fact was more obvious in the mixture containing 50\% 5-15 mm and 50\% 15 $25 \mathrm{~mm}$ sized aggregates. Strength performance and ultrasonic pulse velocity of permeable concrete mixture were improved by using $20 \%$ fine aggregate and decreasing coarse aggregate grain diameter although the W/C ratio of the mixture increased. However, permeability of pervious concrete decreased with the addition of fine aggregate. This fact was due to the reduction in void ratio of concrete mixture by adding fine aggregate particle acting as a filler. The reverse results were obtained in the absence of fine aggregate.

\section{REFERENCE}

[1] Mrakovčić, S., Čeh, N., Jugovac,V., (2014) "Effect of aggregate grading on pervious concrete properties", GRAĐEVINAR 66(2), 107-113

[2] Lian C, Zhue Y, Beecham S. (2011) The RelationshipBetween Porosity and Strength For Porous Concrete. Construction and Buildings Materials 25 (11), 4294-4298 
[3] Kajio, S., Tanaka, S., Tomita, R., Noda, E., Hashimoto, S., (1998), "Properties of Porous Concrete with High Strength", Proceedings 8th International Symposium on Concrete Roads, Lisbon, pp 171-177.

[4] Tennis, P.D., M.L. Leming, D.J. Akers, (2004), "Pervious Concrete Pavements". Special publication by the Portland Cement Association and the National Ready Mixed Concrete. Association, ISBN 0-89312-242-4.

[5] Cem K., Tümer A., (2012), "Farklı Agrega Dağılımına Sahip Geçirimli Betonların ncelenmesi”, Hazır Beton, 79-84.

[6] Shehata M., (2010), "Optimizing the strength and permeability of pervious concrete",. Ryerson University, Department of Civil Engineering.

[7] Chen, Y., Wang,K., Wang, X., ,Zhou, W, Z. (2013), “Strength, Fracture and Fatigue of Pervious Concrete”. Construction and Building Materials, 42, 97-104.

[8] Schaefer VR, Wang K, Sulieman MT, Kevern JT. (2006) Mix design development for pervious concrete in cold weather climates. Final report, Iowa Department of Transportation, National Concrete Pavement Technology Center, Iowa Concrete Paving Association; February. p. 67.

[9] Haselbach LM, Valavala S, Montes F. (2006) Permeability predictions for sand-clogged Portland cement pervious concrete pavement systems. J Environ Manage;81:42-9.

[10] Bentz DB (2008),Virtual pervious concrete: microstructure, percolation, and permeability. ACI Mater J;105(3):297-301.

[11] Scholz M, Graboweiki P. (2007) Review of permeable pavement system. Bulid Environ;42:3830-6.

[12] Huang B, Wu H, Shu X, Burdette EG. (2010) Laboratory evaluation of permeability and strength of polymer-modified pervious concrete. Constr Build Mater;24:818-23.

[13] Tyner JS, Wright WC, Cobbs PA. (2009) Increasing exfiltration from pervious concrete and temperature monitoring. J Environ Manage;90:2636-41.

[14] Tho-in, T., Sata, V., Chindaprasirt, P., Jaturapitakkul, C., (2012). Pervious high-calcium fly ash geopolymer concrete. Construction and Building Materials, 30, 366-371.

[15] NRMCA 900. (2004), Freeze thaw resistance of pervious concrete. Spring Street, Silver Spring, MD 20910, www.nrmca.org. NRMCA National Ready Mixed Concrete Association.

[16] Gomez-Ullate, E., Castillo-Lopez, E., Castro-Fresno, D., Joseba Rodriguez Bayon, JR., (2011) Analysis and Contrast of Different Pervious Pavements for Management of StormWater in a Parking Area in Northern Spain, Water Resources Management; 25(6):1525-1535. 
[17] Jing Y., Guoling J.,(2003), "Experimental Study on Properties of Pervious Concrete Pavement Material", Cement and Concrete Research, 33:381-386.

[18] Meininger R., (1988), No Fines Pervious Conrete For Paving, Concrete International, 2027.

[19] Neptune, A.I., Putman, B.J., (2010), Efect of Aggregate Size and Gradation on Pervious Concrete Mixtures, ACI Materials Journal, 523-528.

[20] Chen Y., Wang K., Wang X., Zhou W., (2013) Strength, fracture and fatigue of pervious concrete, Construction and Building Materials, Volume 42, May 2013, Pages 97-104

[21] Bing C., Liu, J., Li, P., (2008), "Experimental Study on Pervious Concrete", 9th International Confererence on Concrete Pavements, San Francisco, California, August 17-21, pp.202-211.

[22] Vancura, M., MacDonald, K., Khazanovich, L., (2011), "Microscopic analysis of paste and aggregate distresses in pervious concrete in a wet, hard freeze climate", Cement Concrete Composites, 33, (10), 1080-1085.

[23] Kim YJ., Gaddafi A., Yoshitake I., (2016) Permeable concrete mixed with various admixtures, Materials \& Design, 100:110-119.

[24] Huang H., Liu B., Xi K., Wu T., (2016) Interfacial tensile bond behavior of permeable polymer mortar to concrete, Construction and Building Materials, 121:210-221.

[25] Liu J., Miao C., Chen C., Liu J., Cui G., (2013) Effect and mechanism of controlled permeable formwork on concrete water adsorption, Construction and Building Materials, 39:129-133.

[26] Ullate E.G., Lopez, E.C., Fresno, D.C., Bayon, J.B., (2011), Analysis and Contrast of Different Pervious Pavements for Management of Storm-Water in a Parking Area in Northern Spain” Water Resour Manage, 25, 1525-1535.

[27] Mary V., Kevin M. (2011) Microscopic Analysis of Paste and Aggregate Distresses in Pervious Concrete in a Wet Hard Freeze climate, (CCC) Cement Concrete Composites.

[28] Parka, S.B., and Tiab, M., (2004), “An experimental study on the water-purification properties of porous concrete", Cement and Concrete Research, 34, 177-184.

[29] Neithalath, N., Deo, O., Sumanasooriya, M., (2010), "Characterizing pore volume, sizes, and connectivity in pervious concretes for permeability prediction", Materials Characterization, 61,(8),802-813.

[30] Kuo, W.T., Liu, C.C., Su, D.S., (2013), "Use of washed municipal solid waste incinerator bottom ash in pervious concrete", Cement \& Concrete Composites, 37, 328-335. 
[31] Neithalath N., Weiss J., Olek J. (2010) Predicting the Permeability of Pervious Concrete (Enhanced Porosity Concrete) from Non-Destructive Electrical Measurements. Clarkson University, Department of Civil and Environmental Engineering.

[32] Whitehurst E.A. Soniscope test concrete structure, J. Am. Concr. Inst. 1951;47:443-444.

[33] Banthia N, Member, ASCE, Michel Pigeon M, Marchand J, Boisvert J. Permeability of roller compacted concrete. Journal of Materials in Civil Engineering 1990;4(1): 27-40.

Table 1. Some physical, chemical and mechanical properties of cement

\begin{tabular}{|c|c|c|c|c|c|}
\hline \multicolumn{3}{|c|}{ Chemical properties } & \multicolumn{3}{|c|}{ Mechanical and physical properties } \\
\hline Oxide & $(\%)$ & & Properties & & Cement \\
\hline $\mathrm{SiO}_{2}$ & 19.13 & \multirow{3}{*}{\multicolumn{2}{|c|}{ Compressive strength (MPa) }} & 2 Day & 23.5 \\
\hline $\mathrm{Al}_{2} \mathrm{O}_{3}$ & 5.10 & & & 7 Day & 38.6 \\
\hline $\mathrm{Fe}_{2} \mathrm{O}_{3}$ & 3.51 & & & 28 Day & 48.4 \\
\hline $\mathrm{CaO}$ & 63.29 & \multirow{3}{*}{ Fineness } & \multicolumn{2}{|c|}{ Blaine Specific Surface $\left(\mathrm{cm}^{2} / \mathrm{g}\right)$} & 3680 \\
\hline $\mathrm{MgO}$ & 1.06 & & \multicolumn{2}{|c|}{ Residual of $0.090 \mathrm{~mm}$ sieve (\%) } & 1.1 \\
\hline Free $\mathrm{CaO}$ & 0.96 & & \multicolumn{2}{|c|}{ Residual of $0.032 \mathrm{~mm}$ sieve (\%) } & 23.4 \\
\hline $\mathrm{Na}_{2} \mathrm{O}$ & 0.34 & & & & \\
\hline $\mathrm{K}_{2} \mathrm{O}$ & 0.77 & & & & \\
\hline $\mathrm{SO}_{3}$ & 2.83 & & & & \\
\hline LOI & 3.51 & & & & \\
\hline
\end{tabular}

Table 2. Particle size distribution of coarse and fine aggregates

\begin{tabular}{cccc}
\hline $\begin{array}{c}\text { Sieve size } \\
(\mathrm{mm})\end{array}$ & $0-3 \mathrm{~mm}$ & $5-15 \mathrm{~mm}$ & $15-25 \mathrm{~mm}$ \\
\cline { 2 - 4 } 32 & 100 & 100 & 100 \\
16 & 100 & 100 & 5 \\
8 & 100 & 42 & 3 \\
4 & 100 & 2 & 0 \\
2 & 75 & 0 & 0 \\
1 & 53 & 0 & 0 \\
0.50 & 27 & 0 & 0 \\
0.25 & 14 & 0 & 0 \\
\hline
\end{tabular}

Table 3. Physical properties of coarse and fine aggregates

\begin{tabular}{lccc}
\hline & $\mathbf{0 - 3} \mathbf{~ m m}$ & $\mathbf{5 - 1 5} \mathbf{~ m m}$ & $\mathbf{1 5 - 2 5} \mathbf{~ m m}$ \\
\hline Loose bulk density $\left(\mathrm{kg} / \mathrm{m}^{3}\right)$ & 1793 & 1504 & 1395 \\
Surface saturated dry specific gravity & 2.61 & 2.64 & 2.67 \\
Water absorption capacity $(\%)$ & 0.67 & 0.21 & 0.35 \\
\hline
\end{tabular}

Table 4. Corrected mix proportions and designations of the permeable concrete mixtures 


\begin{tabular}{cccccccc}
\hline Mix & \multirow{2}{*}{$\begin{array}{c}\text { Cement } \\
\left(\mathbf{k g} / \mathbf{m}^{\mathbf{3}}\right)\end{array}$} & $\begin{array}{c}\text { Water } \\
\left(\mathbf{k g} / \mathbf{m}^{\mathbf{3}}\right)\end{array}$ & $\begin{array}{c}\text { W/C } \\
\text { ratio }\end{array}$ & $\begin{array}{c}\mathbf{1 5 - 2 5} \mathbf{~ m m} \\
\mathbf{( k g / \mathbf { m } ^ { 3 } )}\end{array}$ & $\begin{array}{c}\mathbf{5 - 1 5} \mathbf{~ m m} \\
\left(\mathbf{k g} / \mathbf{m}^{\mathbf{3}}\right)\end{array}$ & $\begin{array}{c}\mathbf{0 - 3} \mathbf{~ m m} \\
\left(\mathbf{k g} / \mathbf{m}^{\mathbf{3}}\right)\end{array}$ & $\begin{array}{c}\text { Measured } \\
\text { unit weight } \\
\left(\mathbf{k g} / \mathbf{m}^{\mathbf{3}}\right)\end{array}$ \\
\hline $\mathbf{C 1}$ & 310 & 93 & 0.30 & - & 1686 & - & 2089 \\
$\mathbf{C 2}$ & 312 & 94 & 0.30 & 1716 & - & - & 2114 \\
$\mathbf{C 3}$ & 311 & 93 & 0.30 & 1272 & 422 & - & 2098 \\
$\mathbf{C 4}$ & 309 & 93 & 0.30 & 843 & 840 & - & 2084 \\
$\mathbf{C 5}$ & 300 & 90 & 0.30 & 409 & 1225 & - & 2024 \\
$\mathbf{D 1}$ & 312 & 109 & 0.35 & - & 1323 & 336 & 2132 \\
$\mathbf{D 2}$ & 317 & 111 & 0.35 & 1350 & - & 341 & 2169 \\
$\mathbf{D 3}$ & 316 & 111 & 0.35 & 673 & 670 & 340 & 2160 \\
\hline
\end{tabular}

Table 5. Permeability test results

\begin{tabular}{lcccc}
\hline Mix & $\begin{array}{c}\text { The initial water outlet } \\
\text { time from the sample (s) }\end{array}$ & $\begin{array}{c}\text { Water transition time } \\
\text { from the sample (s) }\end{array}$ & $\begin{array}{c}\text { Amount of water } \\
\text { passed from the } \\
\text { sample (ml) }\end{array}$ & $\begin{array}{c}\text { Rate of water } \\
\text { passed from the } \\
\text { sample (\%) }\end{array}$ \\
\hline C1 & 9.0 & 31 & 425 & 85 \\
C2 & 4.7 & 225 & 469 & 94 \\
C3 & 9.7 & 31 & 372 & 74 \\
C4 & 4.4 & 27 & 392 & 78 \\
C5 & 7.2 & 28 & 351 & 70 \\
D1 & 9.2 & 35 & 347 & 68 \\
D2 & 20.0 & 51 & 312 & 62 \\
D3 & 13.0 & 32 & 289 & 59 \\
\hline
\end{tabular}

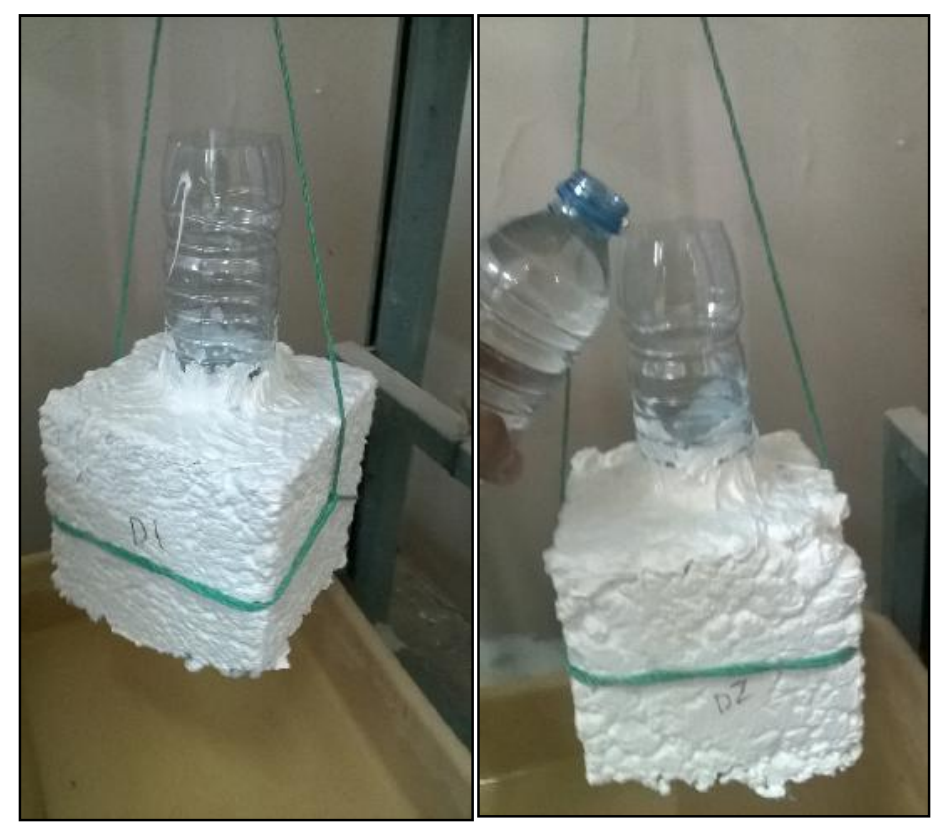

Fig.1. Permeability test 


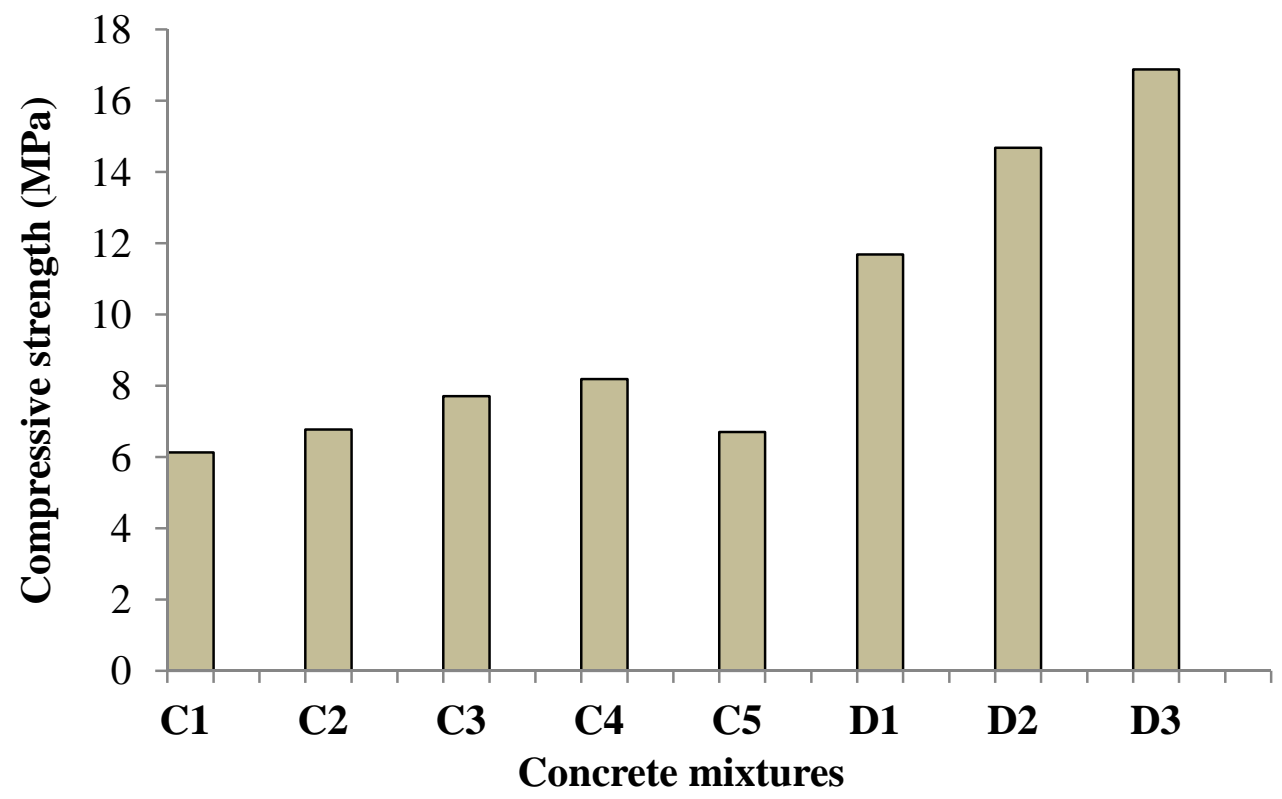

Fig.2. Compressive strength test results of the permeable concrete mixtures

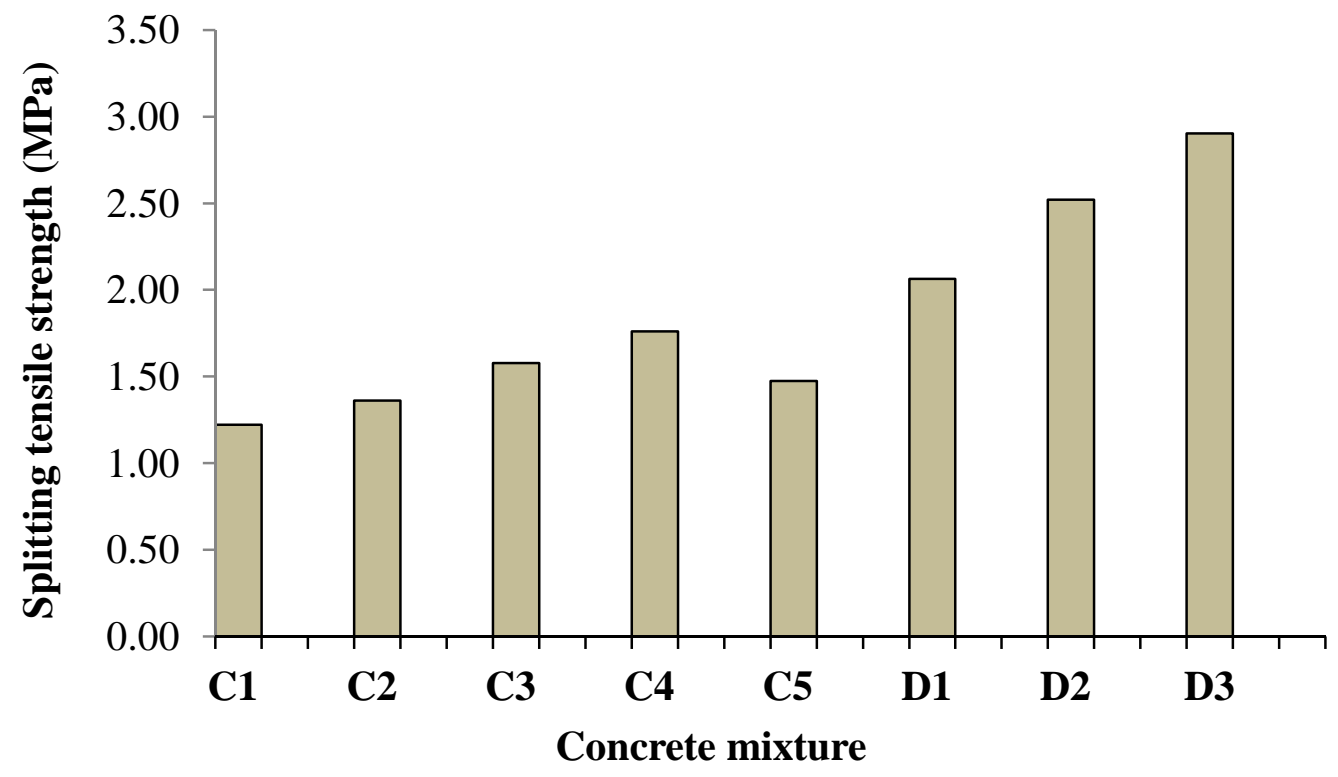

Fig.3. Splitting tensile strength test results 


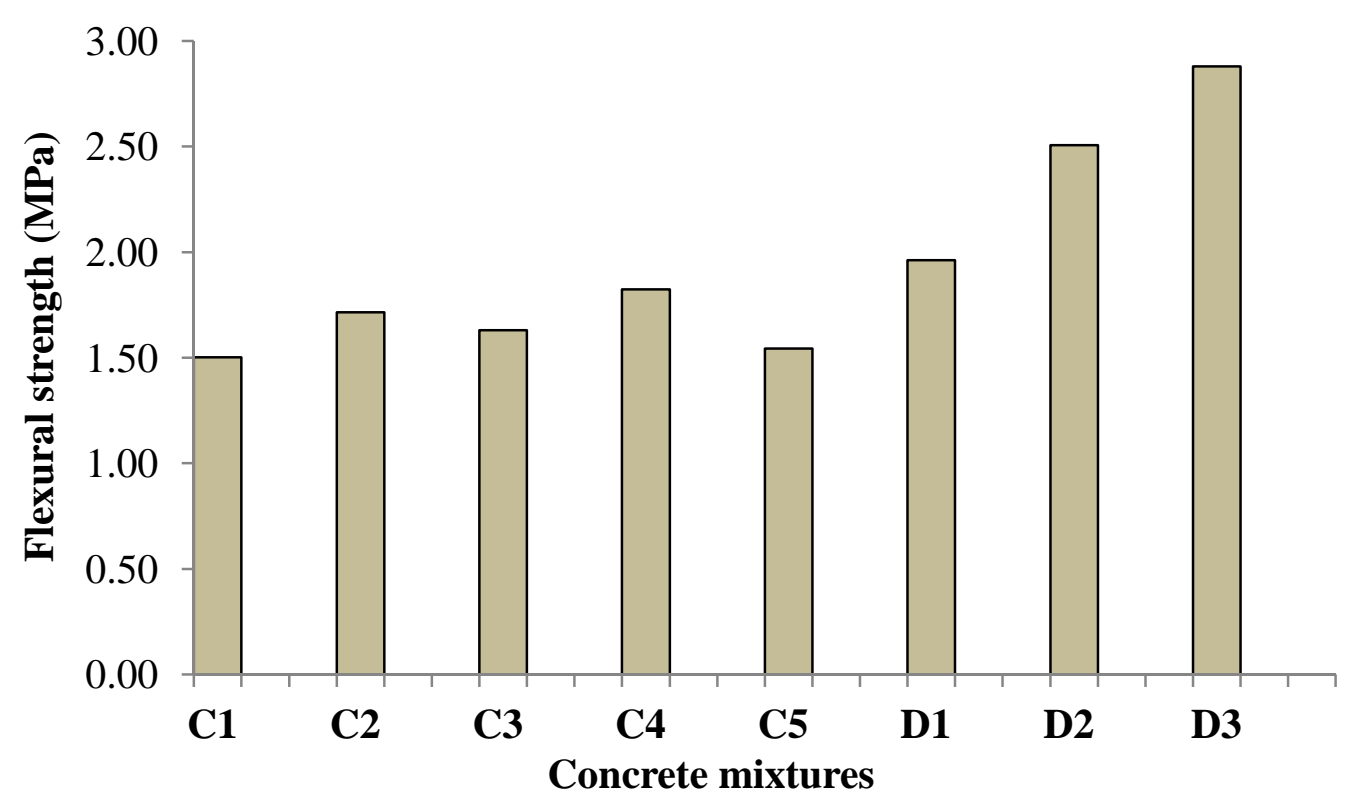

Fig.4. Flexural strength test results 


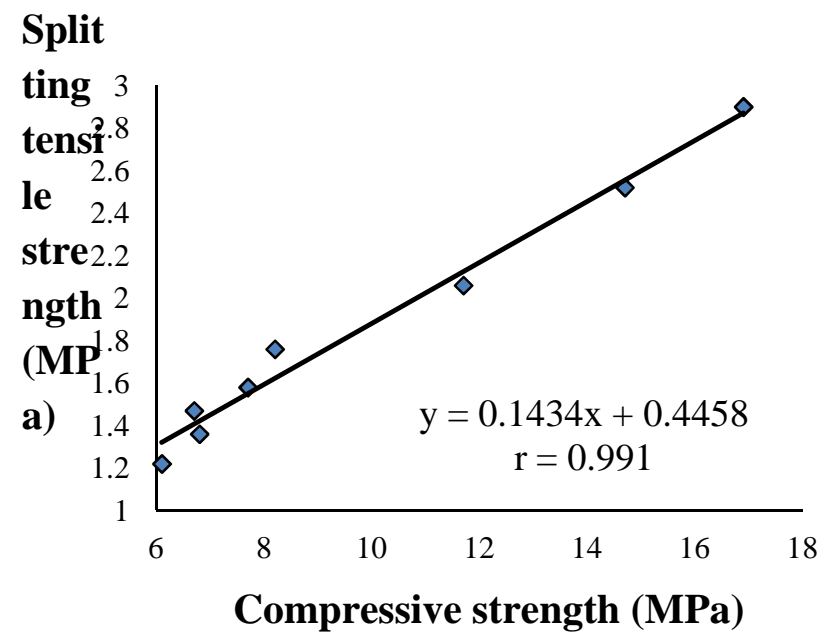

(a)

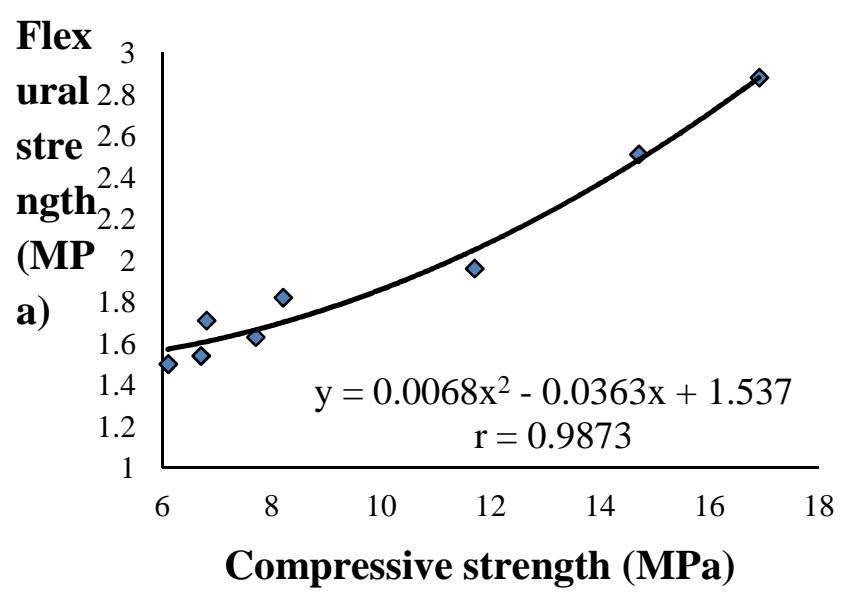

(b)

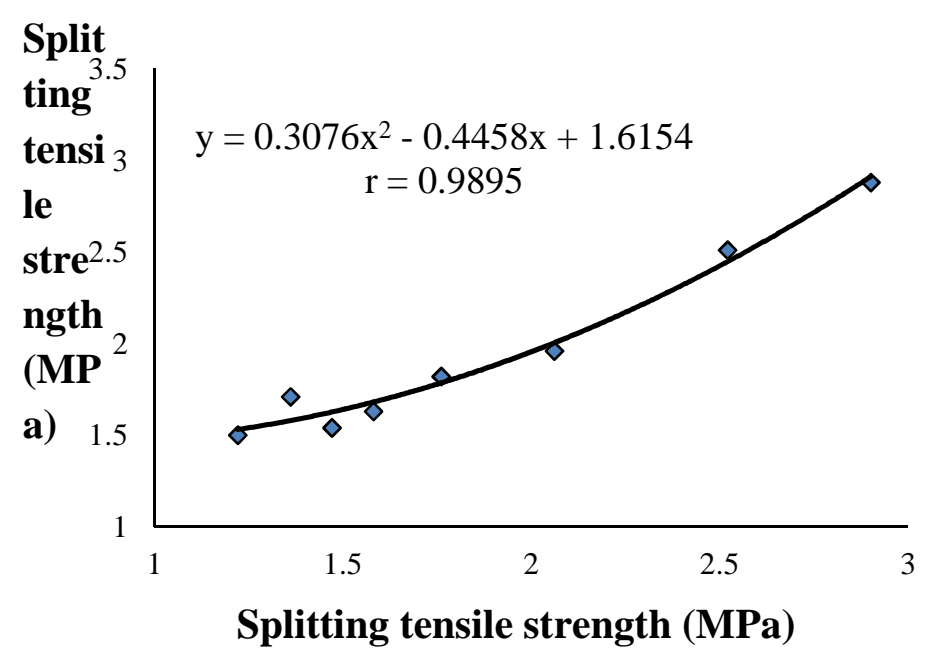

(c)

Fig.5. Strength relationships; a) compressive strength - splitting tensile strength, b) compressive strength - flexural strength c) splitting tensile - flexural strength 


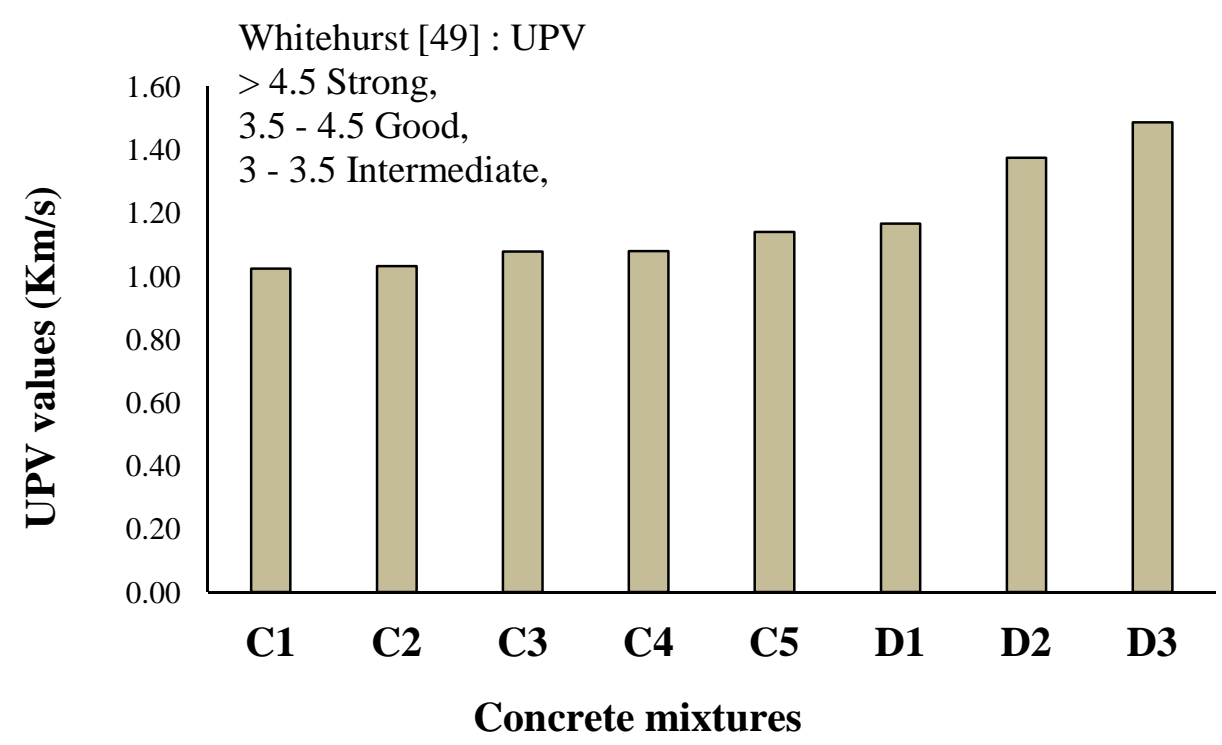

Fig.6. Ultrasonic pulse velocity test results

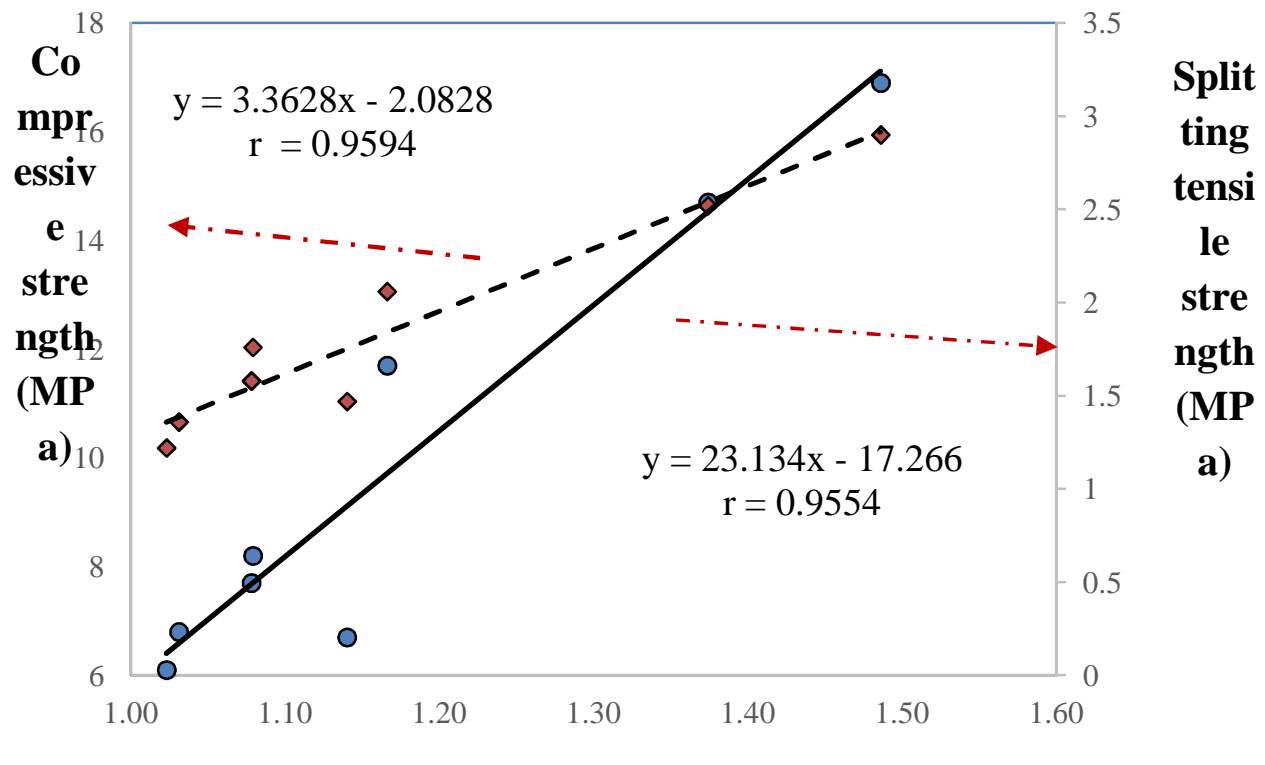

UPV values $(\mathrm{Km} / \mathrm{s})$

Fig.7. Relationship between UPV and -compressive strength and -splitting tensile strength of permeable concrete mixture 


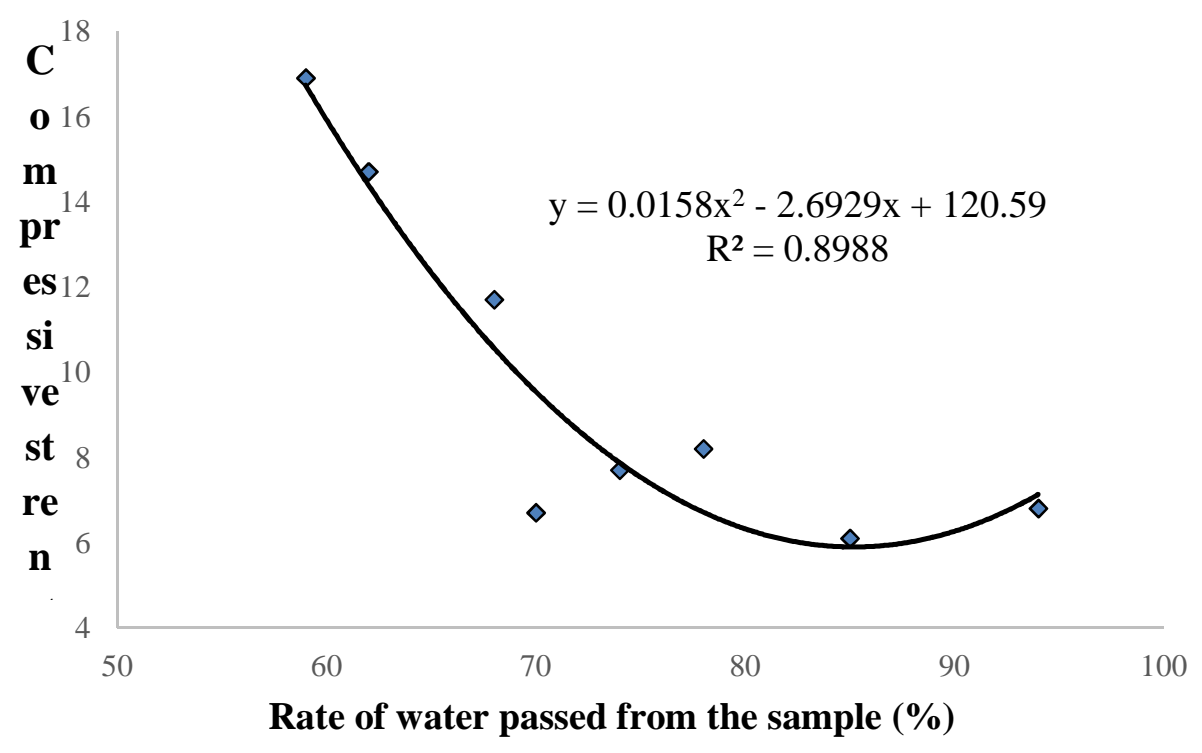

Fig.8. Relationship between compressive strength and rate of water passed from the permeable concrete sample

\section{How to cite this article:}

Yazici Ş, Mardani-Aghabaglou A. Effect of aggregate grain size distribution on properties of permeable concrete. J. Fundam. Appl. Sci., 2017, 9(1), 323-338. 